\title{
Collocations workbook: um material de apoio pedagógico on-line baseado em corpus para o ensino de colocações em inglês
}

\author{
Collocations workbook: a corpus-based online \\ pedagogical support material for the teaching of \\ English collocations
}

Adriane Orenha-Ottaiano

Universidade Estadual Paulista (UNESP), São José do Rio Preto, SP, Brasil.

adriane@ibilce.unesp.br

RESUMO: Esta pesquisa defende que a seleção de colocações para o ensino de língua estrangeira deve ser inicialmente realizada com o propósito de atender aprendizes de uma L1 específica e, desse modo, sustenta que materiais de ensino devam ser elaborados a começar por uma seleção cuidadosa de colocações que retratem as dificuldades específicas desses aprendizes (MACKIN, 1978). Nesse sentido, este artigo visa tratar da compilação de um workbook on-line de colocações na língua inglesa, baseado em corpus, no intuito de permitir que professores de inglês como LE trabalhem com as colocações em sala de aula de modo mais eficiente e auxiliem seus alunos a empregá-las de modo mais preciso e produtivo. Temos também como públicoalvo tradutores aprendizes e profissionais, principalmente aqueles cuja L1 é o português. As atividades estão sendo desenvolvidas com base nas dificuldades dos alunos brasileiros no uso de colocações, segundo dados observados em traduções produzidas por alunos universitários, na direção português-inglês, que compõem um corpus paralelo, o Corpus de Aprendizes de Tradução, bem como de redações, escritas por alunos universitários, que compõem o Corpus de Aprendizes de Lingua Estrangeira. Para extrair os dados, utilizamos o programa WordSmith Tools (SCOTT, 2008), possibilitando-nos levantar os padrões colocacionais mais frequentemente empregados pelos alunos. O Corpus of Contemporary American English (DAVIES, 1990-2012) também é utilizado, para verificar a frequência e recorrência dos padrões colocacionais extraídos, assim como levantar outras colocações para serem incluídas nos 
exercícios que irão compor o workbook. A proposta objetiva contribuir para a conscientização do aspecto colocacional e, principalmente, o desenvolvimento da fluência na língua inglesa.

Palavras-chave: workbook; colocações; corpus; material pedagógico; ensino de colocações.

ABSTRACT: This study argues that the selection of collocations should be geared to targeting L2 learners of a particular L1 background and thus teaching material should be designed with a careful selection of collocations focusing on their specific difficulties (MACKIN, 1978). Bearing that in mind, this article aims at discussing the compilation of an online corpus-based collocational workbook, in order to allow English as a foreign language teachers to work with the collocations in the classroom more effectively and help learners use them more accurately and productively. Our public audience is also learner and professional translators, mainly the ones whose L1 is Portuguese. The activities are being developed based on the difficulties the Brazilian learners had regarding the use of collocations, raised from the translations carried out by university students in the Portuguese-English direction, which comprise a Translation Learner Corpus, as well as essays also written by university students which constitute a Learner Corpus. For extracting the data, the computing program WordSmith Tools (SCOTT, 2008) is used, enabling us to raise the most frequent collocational patterns employed by the learners. We also check frequency and recurrence of collocational patterns extracted as well as raise more collocations to be included in the workbook on The Corpus of Contemporary American English (DAVIES, 1990-2012). The proposal of designing an online workbook has the objective of contributing to Brazilian students' awareness of collocational aspects and mainly to the improvement of fluency in English.

Keywords: workbook; collocations corpus; pedagogical material; teaching collocations.

Recebido em: 14 de agosto de 2015. Aprovado em: 20 de novembro de 2015. 


\section{Introdução}

Segundo explica Kjellmer (1991, p.125), “o léxico mental de qualquer falante nativo é formado não apenas por unidades de palavras simples, mas também por combinatórias de palavras ou colocações". 1 Para o autor, "o domínio dos dois tipos de estrutura constitui parte essencial do equipamento linguístico do falante (seja na produção oral, seja na produção escrita) e the permite mover-se rapidamente, e com o mínimo de esforço, durante a sua exposição de uma estrutura préfabricada para outra",2 (KJELLMER, 1991, p. 125). Nesselhauf (2005) explica que pode ser de interesse por parte de muitos falantes não-nativos e aprendizes de uma LE reduzir o esforço de processamento de unidades fraseológicas mais complexas, de modo a desenvolver a fluência, já que naturalmente necessitam reduzir este esforço, a fim de transmitir de modo mais claro sua mensagem. E, para isso, para desenvolver essa fluência, faz-se necessário ter controle de um grande repertório de unidades pré-fabricadas (WRAY, 2002).

Em nossa experiência de ensino de inglês como língua estrangeira (LE), deparávamos com muitas frustrações por parte dos alunos, os quais costumam dizer que, durante suas viagens ao exterior ou em qualquer situação de comunicação com um falante da língua inglesa durante suas reuniões de negócios, não conseguiam produzir a mesma linguagem desse falante, sentindo-se limitados linguisticamente, devido à dificuldade de combinar as palavras de maneira adequada. Por exemplo, podem conhecer a palavra check, porém, quando desejam utilizar uma unidade fraseológica, em inglês, correspondente a "fazer um cheque", geralmente não sabem qual verbo combinar. Dada a interferência da L1, arriscam-se a dizer to make or to do a check, em vez de to write a check.

1 "The mental lexicon of any native speaker contains single-word units as well as phrasal units or collocations". [Todas as traduções deste trabalho são de nossa responsabilidade.]

2 "Mastery of both types is an essential part of the linguist equipment of the speaker or writer and enables him to move swiftly and with little effort through his exposition from one prefabricated structure to the next". 
Outra dificuldade dos aprendizes brasileiros ocorre em relação às colocações adjetivas. Neste trabalho, definimos colocações como combinações lexicais recorrentes e arbitrárias, que não são expressões idiomáticas, mas que o significado de uma de suas partes é contextualmente restrito àquela combinação específica, com base em Heylen e Maxwell (1994). Tomemos como exemplo o adjetivo wet. Caso desejem causar um efeito e usar, com o adjetivo "molhado" ou "encharcado", um advérbio intensificador como "extremamente", dificilmente produzirão a colocação soaking wet ou dripping wet. $\mathrm{O}$ mesmo ocorre com o adjetivo naked, cujo colocado, além de completely ou entirely, pode ser stark ou buck, empregado para causar maior efeito, formando a combinatória stark naked ou buck naked. Tal situação se dá, em virtude de a primeira atitude do aluno ser a de transferir a combinação da L1 para a LE, o que pode acarretar uma não compreensão por parte do falante da língua inglesa ou, muitas vezes, causar-lhe certa estranheza. Além disso, o sentimento de estar linguisticamente "limitado" pode apontar para a necessidade que alguns tipos de aprendizes têm de se sentir um membro de determinados grupos linguísticos, tais como os executivos acima mencionados, ou tradutores e professores em formação, que fazem parte do público-alvo de nossa investigação. Wray (2002, p. 75) corrobora essa afirmação ao mencionar que o conhecimento de uma grande gama de unidades pré-fabricadas, e nessa esfera incluem-se as colocações, servem para indicar que aquele indivíduo pertence a determinado grupo linguístico, ou seja, os aprendizes "satisfazem o desejo de soar [e escrever] como os demais falantes daquela comunidade".

Vale lembrar que estamos tratando, neste artigo, de um tema bastante específico (ensino de colocações) e de uma área igualmente específica (a Fraseologia) e que, embora tenhamos mencionamos o aprendizado de padrões léxico-gramaticais empregados por nativos da língua inglesa, seguramente não temos a intenção de desconsiderar pesquisas que abordam, por exemplo, o ensino de inglês como língua franca, que não tem como foco as normas da língua inglesa no processo de seu aprendizado e cujos propósitos de pesquisa, bem como públicoalvo, parecem ser bastante diferentes de grande parte de nosso públicoalvo. A própria concepção de Inglês como Língua Franca nos leva a 
notar que também se trata de um ambiente de ensino e aprendizagem da língua inglesa relativamente diferente do nosso, a qual descrevemos a seguir, por meio da definição de Seidlhofer (2001, p. 146, apud SMIT, 2010, p. 46), sobre o que é inglês como língua franca no sentido estrito da palavra:

um sistema adicional de aquisição de língua que serve como meio de comunicação entre falantes de diferentes L1 ou uma língua, por meio do qual os membros de diferentes comunidades linguísticas podem se comunicar, mas que não é a língua materna de nenhum dos falantes envolvidos. ${ }^{3}$

Observamos que, além do ambiente de ensino e aprendizagem de inglês, os próprios interesses e objetivos de grande parte de nosso público-alvo - professores em formação, professores de língua, bem como tradutores em formação ou tradutores profissionais - não se enquadram na concepção de inglês como língua franca e que, portanto, apesar de considerar sua relevância no ensino de inglês, não compartilharemos seus conceitos neste trabalho.

Ainda sobre as dificuldades relacionadas ao aprendizado de colocações, podemos mencionar o fato de que, na grande maioria das vezes, o aprendiz de uma LE não tem consciência de que essas combinações são fixas na língua. Em sua "ingênua" concepção de linguagem (FILLMORE, 1979), o aprendiz acredita que pode combinar as palavras de maneira livre e aleatória. Desse modo, um aprendiz de uma LE poderá ter dificuldades em produzir algumas colocações - a não ser que a colocação correspondente na LE seja literal-, caso não a tenha aprendido de modo explícito ou não haja observado seu uso antes, ou se não tiver sido criadas oportunidades para maximizar oportunidades de aprendizado de modo implícito, já que sua combinabilidade não se dá por critérios semânticos, mas por critérios arbitrários, ditados pela

3 “ (...) an additionally acquired language system that serves as a means of communication between speakers of different first languages or a language by means of which the members of different speech communities can communicate with each other but which is not the native language of either." 
convencionalidade na língua. Hill (2000) igualmente trata dessa questão, ressaltando a importância de conscientizar os aprendizes da existência das colocações na língua, acrescentando a relevância de, ao propor atividades de conscientização, desenvolver também a autonomia no aprendizado das colocações, uma vez que seu processo de aprendizagem é bastante longo. Nesselhauf (2005) também aborda a não consciência (unawareness) dos aprendizes de notar a fixidez na combinabilidade dos elementos que formam uma colocação, assim como sua falta de consciência em relação ao aspecto convencional da língua, ao citar, por parte de aprendizes alemães, o modo exagerado, repetitivo e, na maioria das vezes, inapropriado, do adjetivo big, por exemplo, play a big role ou take biggest pleasure out of.

Pawley e Syder (1983, p. 200) relatam um fato que pode ilustrar uma situação na qual os aprendizes podem não ter aprendido unidades fraseológicas de modo mais explícito ou, ainda, que os alunos, mesmo depois de concluído alguns estágios de aprendizagem da língua inglesa, em sua concepção mais "ingênua", podem não ter percebido a fixidez de tais combinatórias: pode ser observado "nos estágios iniciais de colocar em prática os 'conhecimentos do livro didático' (não importando se o livro é bom ou se o estudo foi bastante profundo), é uma experiência bastante comum descobrirmos que a maior parte da produção dos aprendizes soa, aos ouvidos do nativo ou falante fluente da língua inglesa, como não idiomática"4 - o termo idiomático, nesse caso, tem o significado de natural, típico da linguagem. Os autores (Op. cit.) também observam que, ao comparar a produção de falantes nativos moderadamente fluentes - "inseguros e hesitantes" - com a de aprendizes moderadamente fluentes dessa mesma língua, os falantes nativos fazem consideráveis pausas de hesitação entre sequências de palavras razoavelmente longas, enquanto os aprendizes o fazem depois de cada duas ou três palavras. Esse cenário nos leva a entender que a desigualdade entre os dois grupos consiste em uma diferença na automação da combinabilidade das palavras e, desse modo, na automação das colocações. Dessa forma, Pawley e Syder notam que,

4 'In the early stages of putting one's 'book knowledge' into practice (no matter how good the book and how diligent the study of it), it is common experience to find that most of one's productions are, to the native ear, unidiomatic". 
embora os alunos tenham sido expostos, durante seu processo aprendizado, a uma gama de unidades fraseológicas, tais como as colocações, se não houver instâncias de um ensino explícito dessas unidades, auxiliando-os a ter mais consciência de como as palavras combinam, quais são seus elementos, bem como de seu aspecto fixo e convencional na língua, poderá não haver produção oral nem escrita mais fluente ou natural.

Nesse sentido, podemos notar que, quanto maior o repertório de colocações aprendidas, mais a comunicação pode ser agilizada. Esse domínio facilita a comunicação, já que, uma vez adquiridas e armazenadas, o discurso dá-se com mais rapidez e fluência. $\mathrm{O}$ aprendiz, ao utilizar uma colocação ou unidade multipalavra não esperada pelo falante fluente da língua inglesa, provocará um desvio em seu discurso. Esse tipo de desvio pode ocorrer até mesmo em uma conversa entre nativos, porém, com frequência muito mais baixa. A quebra na convencionalidade na própria L1 também causa estranheza ao ouvinte. No entanto, muitas vezes essa quebra é proposital e pode ser um recurso muito utilizado em propagandas, ou como uma forma de humor e, somente poderá ser compreendida, se o aprendiz conhecer a combinatória, a fim de que perceba como se deu a quebra e entender o humor da frase, fato este imprescindível para um tradutor ou um intérprete. Por exemplo, um falante fluente da língua inglesa, ao comentar a respeito de uma tradução que apresentou sérios erros, diz, em tom de humor, que o tradutor committed a translation (cometeu uma tradução), em vez de usar a colocação correta (did a translation), querendo dizer que o tradutor "acabou" com o texto traduzido, fazendo uma alusão ao verbo to commit em inglês, que possui uma prosódia semântica negativa. Conforme dissemos, o aprendiz, o tradutor e o professor têm de conhecer os padrões da língua inglesa, para que compreendam a quebra colocacional, cujo intuito era exclusivamente de causar um impacto ou criar uma situação de humor.

De acordo com Sinclair (1991), se escolhemos formas não esperadas, a atenção do receptor será direcionada para a forma, e não para o conteúdo. O mesmo não ocorrerá se optarmos por uma forma préfabricada, que não prejudica a concentração do receptor. A respeito desse assunto, cabe mencionar a pesquisa realizada por Altenberg e Eeg- 
Olofsson (1990, p. 2) sobre a compreensão e produção de discurso, tendo como perguntas de pesquisa: "Como falantes competentes de uma língua (ou gênero) conseguem falar de maneira mais fluente do que (ao que parece) sua limitada capacidade de processamento possa permitir? Como intérpretes simultâneos conseguem, de modo análogo, tais proezas miraculosas?". Altenberg e Eeg-Olofsson (1990) concluem que falantes envolvidos em uma interação espontânea, precisam constantemente de expressões facilmente recuperadas do léxico mental e de grandes repertórios de "modos preferenciais" de se dizer as coisas. A esse respeito, Pawley e Syder (2000), Wray (2002) e Nesselhauf (2005) acrescentam que evidências psicolinguísticas mostram que o cérebro humano está muito mais apto a memorizar do que processar e que, desse modo, ter à sua disposição um grande número de unidades pré-fabricadas reduz seu esforço de processar e, portanto, favorece a fluência na língua.

Hausmann (1985), por sua vez, salienta que todo falante estrangeiro necessita conhecer as "palavras satélites" que gravitam em torno das básicas, a fim de entender o funcionamento típico da língua. Fontenelle (1994) igualmente acredita que os aprendizes de uma LE devam ser conscientizados a respeito das colocações e que nós, professores de uma LE, devemos ensiná-los a memorizar essas combinações fixas na língua. Dessa forma, de acordo com o autor, devemos conscientizar os aprendizes dessas restrições e ensiná-los a identificá-las e fazer uso dessas "expressões semicongeladas" que fazem parte da competência fraseológica do falante nativo.

Para justificar o que acabamos de mencionar, vale comentar o que Granger (1998b) descobriu após examinar um corpus de redações em inglês, escritas por falantes nativos da língua inglesa e falantes não nativos (falantes franceses, com nível de conhecimento em inglês avançado). Após aplicar um teste de combinações de palavras a 112 informantes, a autora constatou que aprendizes avançados têm uma consciência muito vaga do que é uma colocação convencional. Raramente detectam desvios de padrões colocacionais. A autora

"How do competent speakers of a language (or genre) manage to talk more fluently than (it appears) their limited processing capacity should permit? How do simultaneous interpreters achieve their seemingly miraculous feats?" 
menciona que a colocação fully different foi rapidamente aceita. Porém, a combinatória bitterly cold foi, na maior parte, rejeitada. Observou também um sobreuso de advérbios, tais como completely e totally, por parte dos falantes não-nativos. Essa observação nos pareceu bastante pertinente, uma vez que chegamos a um resultado bastante semelhante com uma pesquisa feita com aprendizes de inglês brasileiros. ${ }^{6}$ Por não saberem, ou por não terem consciência de que haja um advérbio específico para determinado verbo ou adjetivo, acabam por utilizar sempre os mesmos intensificadores. Os aprendizes brasileiros investigados empregam os advérbios very e completely com uma frequência bastante alta, o que, embora em alguns casos não seja errado, pode tornar o discurso enfadonho e pouco criativo.

A fim de comprovar a importância do ensino de colocações em aulas de inglês como LE, Bahns e Eldaw (1993), realizaram uma pesquisa com 58 alunos universitários que estudaram inglês por num período de 7 a 9 anos antes de entrar para a universidade. Como instrumento de pesquisa, foram aplicados um exercício de tradução e um exercício de preenchimento de lacunas. Chegaram à conclusão de que 1) os alunos não aprendem as colocações de forma implícita e que seu conhecimento colocacional não se desenvolverá da mesma forma que seu conhecimento vocabular; 2) o conhecimento a respeito das colocações é necessário para que o falante possa comunicar-se de modo mais eficiente, já que nem sempre é possível parafrasear as combinatórias; 3) é preciso, sim, ensinar as colocações, tendo como critério a seleção daquelas que não sejam facilmente parafraseadas.

Assim, apesar de comumente empregada na língua e de seu relevante papel no processo de aprendizagem, as colocações ainda são pouco exploradas no ensino de LE, conforme mostram diversas pesquisas na área. Devido à dificuldade na produção, e não na compreensão, o ensino explícito de colocações ou, pelo menos, a maximização de sua exposição ou seu aprendizado em sala de aula,

6 Realizamos pesquisa semelhante mediante a análise de redações escritas por alunos universitários do Curso de Licenciatura em Letras e Bacharelado em Letras com Habilitação para Tradutor, que compõem o Corpus de Aprendizes de Língua Escrita (CALE) e as traduções para o inglês que formam o Corpus de Aprendizes de Tradução (CAT), traduzidos por alunos do Curso de Tradução. 
mostra-se fundamental para um aprendiz que deseja ser fluente em inglês, bem como conhecer diferentes possibilidades de se expressar de modo mais natural, preciso e, em alguns casos, criativo. Em virtude de sua relevância no contexto de ensino-aprendizado, torna-se imprescindível enfatizar seu aprendizado sistemático, por meio de um material didático voltado especificamente para tais combinatórias e, portanto, contribuir para a conscientização do aspecto convencional e colocacional da língua e para a produção de um discurso mais fluente.

Em pesquisa realizada na instituição de origem (Projeto Trienal), durante o triênio 2010-2013, analisamos as escolhas colocacionais, a influência da L1 nessas escolhas, bem como as quebras colocacionais presentes nas traduções e nos textos escritos (redações) dos alunos do Curso de Letras e de Tradução, que respectivamente compõem o Corpus de Aprendizes de Língua Escrita (CALE) e o Corpus de Aprendizes de Tradução (CAT), com o auxílio das ferramentas dos programas computacionais WordSmith Tools (SCOTT, 2008) e AntConc (ANTHONY, 2012). Em seguida, comparamos as opções colocacionais sugeridas pelos alunos com as colocações mais frequentemente empregadas por falantes fluentes da língua inglesa, constantes nos corpora on-line British National Corpus ${ }^{7}$ e Corpus of Contemporary American English, ${ }^{8}$ que representam a língua em seu contexto real de uso e mais comumente empregada por falantes fluentes da língua inglesa. Com base nas dificuldades colocacionais enfrentadas pelos alunos, selecionamos algumas colocações que deverão fazer parte do material proposto e, dessa maneira, atender às necessidades de brasileiros aprendizes de inglês como LE, como também sanar suas dificuldades, possibilitando um aprendizado sistemático dessas unidades fraseológicas.

Além de começar das palavras-chave e colocações extraídas dos corpora de aprendizes (CALE e CAT), visamos selecionar e analisar palavras com base na lista dos lemas mais frequentes (60.000 e 100.000)

7 Disponível em: <http://www.natcorp.ox.ac.uk/>, o British National Corpus é composto de 100 milhões de palavras, das quais disponibiliza 50 milhões na Internet.

8 Disponível em: $<$ http://corpus.byu.edu/coca/>, o Corpus of Contemporary American English é formado por 450 milhões de palavras. 
no The Corpus of Contemporary American English (COCA), com vistas a, com base nesse levantamento, extrair outros padrões colocacionais nos corpora de referência acima citados. O propósito dessa seleção e análise é garantir que um maior número de colocações frequentemente empregadas por falantes da língua inglesa estejam inseridas no workbook.

Nesse sentido, o objetivo principal deste artigo é tratar da compilação e da relevância do Online English Collocations Workbook, baseado em corpus, com foco no ensino das colocações (adjetivas, verbais, nominais e adverbiais) mais frequentemente empregadas na língua inglesa, por meio de atividades e jogos interativos. Dada a escassez de materiais de apoio que contemplem unidades fraseológicas do tipo colocação, a obra proposta busca também preencher essa lacuna. Além disso, vale mencionar que poderá ser utilizada não apenas por alunos da instituição em que atuamos mas também por aprendizes de todo o país, principalmente pelo fato de ser acessada via Internet, caracterizando novamente a proposta como inédita tanto em âmbito nacional quanto, de certo modo, internacional.

Por questões de delimitações orçamentárias, esta pesquisa contempla a primeira e a segunda fase de elaboração do workbook, disponibilizando, assim, o Memory Game (Jogo da Memória) e a atividade Gap Fill ("Completar espaços"), que consiste em completar frases ou trechos de textos por meio de colocações pré-definidas. Como fase seguinte, pretendemos, em pesquisa futura, adicionar outros tipos de jogos, a fim de oferecer diferentes possibilidades de memorização das colocações, também buscando atender a diversos estilos e formas de aprendizagem.

\section{Fundamentação Teórica}

Neste capítulo, abordamos os conceitos teóricos que embasam o desenvolvimento da pesquisa. Tratamos da convencionalidade e de sua importância na compreensão dos fraseologismos. De modo mais específico, apresentamos o conceito de colocação, algumas de suas características, bem como sua taxonomia. Além disso, faz-se necessário 
discutir a conceituação de corpus e corpora de aprendizes, de sua definição e importância para o ensino de línguas e para a tradução.

\subsection{Convencionalidade, fraseologismos e colocações}

O termo "convencionalidade" na língua está relacionado ao uso que fazemos, ao interagir, de uma série de convenções, expressões e blocos de palavras já preestabelecidos e consagrados em nossa comunidade. É por isso que, quando esbarramos em alguém, por exemplo, dizemos "(me) desculpe". Essa expressão faz parte de um costume social consagrado e previsível; não fazer uso dela, em tal situação, implicaria falta de educação, pois uma pessoa considerada educada pediria desculpas automaticamente, segundo rezam as regras e convenções sociais já estabelecidas.

Outro exemplo de convencionalidade na língua é a expressão idiomática "Matei dois coelhos com uma cajadada só". Logo vem à mente de nosso interlocutor / falante nativo a ideia de que conseguimos realizar duas coisas ao mesmo tempo. Não passa pela cabeça de um falante nativo que, literalmente, tenhamos matado dois coelhos com uma cajadada, ou seja, não há uma relação analógica entre o significante e o real significado dessa expressão, uma vez que seu significado metafórico já está cristalizado na língua. Observamos, desse modo, um exemplo de convencionalidade em uma situação social, no primeiro caso, e em uma situação linguística, no segundo.

A convencionalidade também está ligada ao aspecto da arbitrariedade na língua. Ao empregar a expressão "Matar dois coelhos com uma cajadada só", usamos, em português, um animal - o "coelho". Em inglês, há uma expressão equivalente: To kill two birds with one stone, em que o "coelho" é substituído por uma ave - o "pássaro". Observamos que até mesmo a forma de matar é diferente nas duas línguas: em português com uma "cajadada" e, em inglês, com uma "pedra". O mesmo ocorre com a expressão "trabalhar como um burro", no português, e to work like a dog ou to work like a horse, em inglês. O animal associado ao trabalho árduo em português é o "burro" e, no inglês, o "cavalo" ou o "cachorro". Por esses exemplos, nota-se que tais 
escolhas deram-se de maneira arbitrária e, assim, ficaram convencionalizadas nas duas línguas.

O termo convencionalidade foi empregado por Fillmore (1979) para designar "o conjunto dos elementos linguísticos, cuja coocorrência não é explicada sintática ou semanticamente, mas, sim, pelo uso". Fillmore (1979) também chama a atenção para o fato de a convencionalidade estar intimamente relacionada à fluência em uma língua, ou seja, o desconhecimento de unidades convencionais pode fazer com que o aprendiz não se comunique de maneira eficiente. A convencionalidade está relacionada aos usos e costumes sociais já preestabelecidos e consagrados pela comunidade. Está igualmente associada às normas de procedimento em determinadas situações e à linguagem dentro dessa mesma comunidade.

Ao tratar da convencionalidade, cabe discutir os fraseologismos na língua e no campo do aprendizado de uma LE. Fillmore (1979, p. 66) apresenta o aprendiz de uma LE como o "falante ingênuo", ou seja, aquele falante que desconhece o fator convencionalidade na língua. Consoante o autor, "[...] o ouvinte / falante ingênuo não conhece expressões idiomáticas lexicais e expressões idiomáticas frasais, colocações lexicais, fórmulas situacionais, comunicação indireta, ou as estruturas esperadas de textos de um dado tipo". 9 Ou seja, esse aprendiz faz apenas uma leitura composicional e não idiomática das estruturas linguísticas da língua que está aprendendo, podendo comprometer sua compreensão e produção - oral ou escrita.

Tagnin (2002) expande a noção de Fillmore (1979) ao tradutor, defendendo que "tradutor ingênuo" é aquele que desconhece a convencionalidade de uma língua, de modo que não é capaz de detectar sua ocorrência no texto que traduz, deixando, dessa maneira, de recuperá-la no texto traduzido. Ou seja, o "tradutor ingênuo" também pode fazer uma leitura composicional e não idiomática das estruturas linguísticas do texto de partida, o que, para a tradução de documentos jurídicos, pode comprometer a compreensão do leitor ou ainda ter consequências mais sérias. De acordo com a autora, o tradutor, ao se

9 “[...] the innocent speaker/hearer does not know lexical idioms, phrasal idioms, lexical collocations, situational formulas, indirect communication, or the expected structures of texts of given types". 
prender ao texto fonte, pode não notar que, entre várias formas gramaticais, haja uma opção preferencial. Caso essa escolha não seja a mais adequada na língua de chegada, sua tradução pode não soar "natural".

No que tange aos fraseologismos sob o ponto de vista cognitivo, é sabido que o falante nativo conta com um repertório mais ou menos fixo de expressões armazenadas em seu léxico mental (PAQUOT, 2008; NESSELHAUF, 2005; WRAY, 2002; TER-MINASOVA, 1992). Para simplificar a produção, ele as resgata de maneira automática como um bloco só - de acordo com o seu grau de competência linguística - e não lexema por lexema. Ou seja, não precisará produzi-las novamente no momento de seu discurso:

As unidades fraseológicas têm a mesma função das palavras no discurso. No processo de fala, você não junta meramente as palavras separadas, em uma sucessão linear; você também usa unidades 'prontas', blocos pré-fabricados (i.e., unidades fraseológicas) que já existem na língua como um bloco inteiro e que funcionam, no discurso, como uma única palavra. (TERMINASOVA, 1992, p. 535). ${ }^{10}$

Dessa maneira, o que parece ser espontâneo é, na verdade, uma forma estereotipada, fixa e repetitiva e, se o falante não tiver um repertório amplo ao seu dispor, seu discurso poderá ficar comprometido, no sentido de que não conseguirá se expressar, seja por não combinar as palavras conforme os padrões linguísticos da LE, por exemplo, durante uma entrevista ou reunião de negócios, seja pelo fato de ter que pausar muitas vezes durante sua fala, exatamente por não ter um grande reportório de padrões fraseológicos esperados para aquele contexto,

10 "Phraseological units function in speech in the same way as words. In the process of speaking, one does not merely bring separate words together in linear succession; one also uses "ready-made" units, prefabricated blocks (i.e. phraseological units) that already exist in language as a global whole and function in speech as one word". 
tendo que construir essas unidades fraseológicas no momento de sua fala.

Altenberg e Eeg-Olofsson (1990, p. 2) revelam que "as 'prefabs' desempenham um papel importante no discurso oral, pois podemos dizer que agem como uma espécie de 'piloto automático' que o falante pode ligar, a fim de ganhar tempo para se dedicar aos aspectos criativos e sociais do processo de fala". ${ }^{11}$ Assim, aprendemos nossa L1 dessa maneira, ou seja, em blocos pré-fabricados, como combinatórias prontas que são produzidas de modo automático, sem reflexão, de forma inconsciente. Isso se faz necessário, pois, se a cada vez que discursássemos tivéssemos de formar novamente uma combinação de palavras, além do tempo que perderíamos para elaborar essa combinação, nosso discurso se tornaria enfadonho. Sob o ponto de vista do ouvinte, como ele poderia decodificar um discurso se, a todo momento, o falante criasse novos blocos de palavras? Dessa maneira, o processo de comunicação se tornaria bastante cansativo, tanto por parte do falante quanto do ouvinte.

Observamos, dessa forma, que o ensino de unidades multipalavras e, mais especificamente, de colocações, é de fundamental importância para um falante que deseja ser fluente em uma LE, ou seja, é imprescindível enfatizar seu aprendizado sistemático:

Uma língua que é colocacionalmente rica, é também mais precisa. Isso ocorre porque a maioria das palavras da língua inglesa - especialmente as mais comuns - adotam uma grande variedade de significados, alguns bem distintos e alguns que variam entre si por graus. O significado preciso em qualquer contexto é determinado por aquele contexto: pelas palavras que circundam e combinam com a palavra núcleo - pela colocação. Um aluno que escolher a melhor colocação se expressará de maneira muito mais clara e será capaz de transmitir não apenas

11 "Prefabs play a major part in spontaneous spoken interaction, [...] where they can be said to act as a kind of 'autopilot' which the speaker can switch on to gain time for the creative and social aspects of the speech process". 
um significado geral mas também algo bem preciso (MCINTOSH; FRANCIS; POOLE, 2009, p. v). ${ }^{12}$

Dessa maneira, em uma situação jurídica, por exemplo, o aprendiz deverá conhecer a colocação mitigating factors ou mitigating circumstances (em "circunstâncias atenuantes"), já que se trata de colocações bastante específicas, cujo colocado (mitigating) raramente coocorre com outras palavras. Isso se deve, pois, se tentar explicar somente que foi citado um fato que abranda a culpa do réu, seu discurso não terá o mesmo impacto e especificidade. Da mesma forma que, se quiser dizer que "o local estava um breu", de tão escuro que estava, e empregar somente the place was very dark, poderá não ser tão específico ou claro caso tivesse empregado a colocação pitch dark (the place was pitch dark).

Com base nesse cenário, passamos a tratar das colocações sob a ótica da Fraseologia. Trata-sede um dos tipos de fraseologismos que, por sua vez, estão inseridos no âmbito da convencionalidade, consoante a figura abaixo:

12 "Language that is collocationally rich is also more precise. This is because most single words in the English language - especially the more common words embrace a whole range of meanings, some quite distinct, and some that shade into each other by degrees. The precise meaning in any context is determined by that context: by the words that surround and combine with the core word - by collocation. A student who chooses the best collocation will express himself much more clearly and be able to convey not just a general meaning, but something quite precise". 
Figura 1 - Convencionalidade, Fraseologismos e Colocações

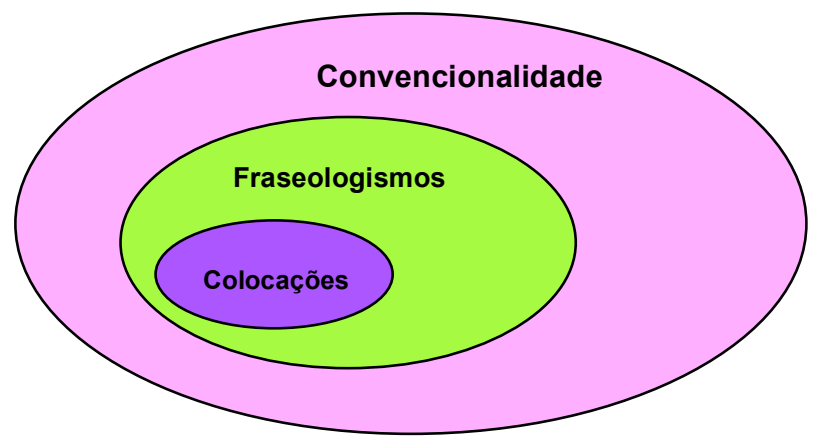

Fonte: ORENHA-OTTAIANO, 2004.

Estando no âmbito da convencionalidade, as colocações, bem como alguns tipos de fraseologismos, representam um problema de produção, e não de compreensão, ou seja, é perfeitamente possível compreendê-las, na maioria dos casos, como em place an order e pay a complimentdesde que o aluno conheça o significado de order e compliment. Entretanto, um falante não nativo poderia ter mais dificuldade para produzi-las e muitas vezes, influenciado por sua língua-mãe, segundo também apontam pesquisas de Nesselhauf (2005) e Paquot (2008), acabaria cometendo quebras colocacionais, como faz ao produzir a colocação "fazer um pedido" por make an order e "fazer um elogio" por make a compliment, compreensíveis por parte de um falante fluente da língua inglesa, embora possam soar um tanto estranhas. Diferentemente de uma expressão idiomática, que esse mesmo falante não nativo poderia ter grande dificuldade não só de produzi-la mas também de compreendêla, como em: Peter is a bit thin on the top. Se o aprendiz ainda não tiver se deparado com essa expressão, tampouco observar o contexto em que estiver inserida, provavelmente não compreenderá seu significado: "Peter é careca".

De acordo com Firth (1957), colocações são palavras que mostram uma coocorrência habitual sob o ponto de vista sintagmático. Halliday (1961, p. 75), discípulo de Firth (1957), apresenta uma definição bastante semelhante ao dizer que "uma colocação é uma 
associação sintagmática de itens lexicais [...]". Halliday (1961), assim como Firth (1957), salientou a importância de um nível lexical distinto do gramatical, para explicar aspectos que a gramática não era capaz de explicar. $\mathrm{O}$ autor menciona que podemos dizer tanto strong argument $(=$ "forte argumento") quanto powerful argument (= "poderoso argumento"). No entanto, dizemos preferencialmente strong tea (relacionado à cor do chá) e powerful car (= "um carro potente"), enquanto powerful tea e strong car não são frequentes. A combinação powerful tea poderia até ser empregada no sentido de se tratar de um "chá poderoso", com poderes talvez curativos. Já o adjetivo strong combinado com car poderia se referir a uma característica física do "carro".

Mediante o exposto, buscamos tecer algumas considerações a respeito da convencionalidade na língua e apresentar alguns conceitos acerca das colocações. Na subseção seguinte, tratamos da definição, delimitação e taxonomia das colocações, sob a ótica de Hausmann (1984, 1985).

2.2 A Proposta de Hausmann: delimitação e taxonomia das colocações

Outro autor que muito contribuiu para a descrição e definição de colocações foi Hausmann (1985), cujas ideias ainda não foram condensadas em uma única obra. Vários autores alemães citam seus trabalhos, mas nossos comentários contaram com o apoio de artigos em inglês e em português.

Hausmann (1985) tem importância fundamental para esta pesquisa, por ter descrito as colocações sob pontos de vista que também abordamos em nosso trabalho, segundo nos mostra Heid et al. (1991, p. 12):

- a construção de entradas de dicionários (HAUSMANN,1988), e de dicionários de colocações especializados; 
- a aprendizagem de vocabulário: a relevância das colocações para o aprendizado e os aspectos pedagógicos das colocações em dicionários (HAUSMANN, 1984); e

- o estudo do fenômeno das colocações e suas implicações gerais para a Lexicografia (HAUSMANN, 1985).

O pesquisador faz uma distinção básica entre combinações fixas e nãofixas. As combinações fixas são as expressões idiomáticas e os compostos ("mercado negro", por exemplo, uma vez que são lexemas que correspondem a um conceito). Já as combinações não-fixas referemse à coocorrência dos signos.

O critério que distingue a coocorrência dos signos é a "afinidade", utilizada por Hausmann no sentido de disponibilidade da combinação, na medida que chama as colocações de "produtos semiacabados de uma língua" (semi-finished products of a language). Segundo o autor, o ponto essencial das colocações reside em seu "status de disponibilidade mental como um todo, como um bloco só, e não como uma criação produzida ad hoc por um falante" "13 (HAUSMANN, 1984, apud HEID et al., 1991, p. 15).

Para Hausmann (1984), o aspecto da lexicalização é muito importante para a definição de colocação e sua inserção em obras lexicográficas. Segundo ele, os usuários de uma língua simplesmente "reutilizam" os "produtos semiacabados" da língua quando utilizam as colocações.

No que se refere aos dois elementos da colocação - a base e o colocado -, consoante a terminologia de Hausmann (1984), esses não possuem o mesmo status semântico na combinação. Na verdade, há uma hierarquia entre esses elementos, pois um determina e o outro é determinado. Aquele que determina é chamado de base, que é o elemento autônomo, enquanto o outro, o determinado, é chamado de colocado, que somente pode ser interpretado semanticamente quando na colocação. Simplificando, a base é aquilo que já sabemos e o colocado aquilo que

\footnotetext{
13 “(...) status of mental disponibility as a whole, not as a creation produced ad hoc by a speaker".
} 
estamos buscando, por exemplo, em issue shares, shares é a base e issue é o colocado.

Resumidamente, a base é:

- um elemento independente;

- semanticamente autônoma;

- traduzível, independentemente de seu uso na colocação; e

- determina padrões lexicais que podem combinar com ela.

Quanto ao colocado:

- funciona como um conceito modificador;

- é semanticamente interpretável somente dentro da colocação;

- sua tradução depende do uso na colocação;

- é escolhido por uma dada base para formar uma colocação (HEID et al., 1991).

No que se refere à taxonomia das colocações, Hausmann (1985) sugere uma classificação, a qual apresentamos abaixo, com exemplos tirados dos corpora de nossa pesquisa:

VERBAIS - com quatro formas básicas:

- Verbo colocado + Substantivo base: acquire shares; develop an illness

- Substantivo base + Verbo colocado: investments dropped

- Verbo colocado + Preposição + Substantivo base: dispose of shares; 
- Verbo colocado + Partícula Adverbial ${ }^{14}+$ Substantivo base: set up a business

- Verbo colocado + Adjetivo base: grow strong

NOMINAIS - com duas formas básicas:

- Substantivo base + Substantivo colocado: share subscription;

- Substantivo colocado + Preposição + Substantivo base: holder of shares; an attack of flu

ADJETIVAS - com uma forma:

- Adjetivo colocado + Substantivo base: bearer shares; lifethreatening illness

ADVERBIAIS - com três formas básicas:

- Advérbio colocado + Adjetivo base: fully eligible

- Verbo base + Advérbio colocado: drop dramatically

- Advérbio colocado + Verbo base: fully paid; duly appointed

Conforme mencionamos, o workbook tratará de todos os tipos de colocação.

14 No caso dos phrasal verbs em inglês. 
2.3 Corpus e Corpora de Aprendizes: definição e importância para o ensino de línguas e para a tradução

Com referência ao termo corpus, objeto da Linguística de Corpus, Berber Sardinha (2004, p.18) define-o como:

um conjunto de dados linguísticos (pertencentes ao uso oral ou escrito da língua, ou a ambos), sistematizados segundo determinados critérios, suficientemente extensos em amplitude e profundidade, de maneira que sejam representativos da totalidade do uso linguístico ou de algum de seus âmbitos, dispostos de tal modo que possam ser processados por computador, com a finalidade de propiciar resultados vários e úteis para a descrição e análise (BERBER SARDINHA, 2004, p.18).

Tognini-Bonelli (2001, p. 55) sugere uma definição que se mostra bastante coincidente com a definição anterior. Segundo a autora, “(...) um corpus é uma coletânea de textos autênticos e computadorizados, passível de análise ou processamento automático ou semi-automático". 6 Ela acrescenta ainda que os textos são selecionados de acordo com critérios explícitos, a fim de apreender as regularidades de uma língua, de uma variedade de língua, ou de uma sub-língua.

$\mathrm{Na}$ área de ensino-aprendizagem de línguas estrangeiras, são inegáveis os benefícios advindos do uso de corpora em sala de aula, sem a pretensão de descartar outras metodologias, abordagens e ferramentas já utilizadas. Segundo defende Bernardini (2004, p. 31-32), “(...) corpora e ferramentas de análise de corpus podem oferecer um dos instrumentais mais potentes disponíveis até hoje para atividades de aprendizagem para

6 “(...) a corpus is taken to be a computerized collection of authentic texts, amenable to automatic or semi-automatic processing or analysis". 
descoberta em sala de aula". ${ }^{15}$ Dessa forma, o uso de corpora em sala de aula pode facilitar o aprendizado de uma LE, uma vez que permite o aluno observar os itens lexicais em contexto e o insere no processo ensino-aprendizagem.

No tocante a corpora eletrônicos de aprendizes, de acordo com Granger, Hung e Petch-Tyson (2002, p. 7), referem-se a "coletâneas eletrônicas de dados textuais em uma segunda língua ou em uma LE, compilados de acordo com critérios de desenho explícitos, a fim de atender a um propósito específico, no que se refere à aquisição de segunda língua ou ao ensino de LE". ${ }^{16}$ Cabe lembrar, que os referidos dados textuais podem ser formados por textos escritos ou orais (por meio de transcrições).

Para inserir um texto em um corpus de aprendizes, é necessário seguir uma série de critérios, previamente estabelecidos, para que todos os textos que compõem este corpus apresentem uma homogeneidade quanto ao gênero textual, à temática, à extensão dos textos e ao nível de língua. De acordo com o projeto ICLE (International Corpus of Learner English), coordenado por Granger (1993), por exemplo, os textos dos aprendizes deverão ser, obrigatoriamente, argumentativos. Há também alguns temas, entre os quais deverão escolher, tais como: Crime does not pay, Feminism has done more harm to the cause of women than good, Pollution: a silent conspiracy etc. Além disso, as redações deverão conter de 500 a, no máximo, 1.000 palavras, entre outros dados.

Entre os corpora de aprendizes, podemos citar o ICLE, coordenado por Granger (1993), ${ }^{17}$ composto por redações de alunos de nível intermediário superior e avançado; o Longman Learner's Corpus, sob a supervisão de Summers (1999); o Cambridge Learners' Corpus, sob a responsabilidade de Nicholls (1999); e o Multilingual Learner

15 “(...) corpora and corpus analysis tools seem to provide one of the most powerful tools made available to date for classroom discovery learning activities".

16 "Computer learner corpora are electronic collections of authentic FL/SL textual data assembled according to explicit design criteria for a particular SLA/FLT purpose".

17 O projeto ICLE abarca vários corpora, compilados em vários países (um total de 21 países, conforme informação no site $<$ http://cecl.fltr.ucl.ac.be/CeclProjects/Icle/icle.htm $>$ ). No Brasil, a vertente do ICLE é o Br-ICLE, coordenado pelo Prof. Tony Berber Sardinha, no LAEL, Pontifícia Universidade Católica de São Paulo (PUC/SP). 
Corpus, coordenado pela Profa. Stella E. O. Tagnin, da Universidade de São Paulo (USP), entre vários outros.

No que tange ao uso de corpora de aprendizes para o ensino de LE, pesquisadores da área (GRANGER, HUNG, PETCH-TYSON, 2002; BERBER SARDINHA, 2001; TONO, 1999; GRANGER, 1998a) destacam várias aplicações como, por exemplo, a descrição da interlíngua e a preparação de materiais didáticos. Para a área da Lexicografia, a exploração de corpora de aprendizes pode favorecer a compilação de dicionários, de modo geral. Berber Sardinha (2001) também faz referência às vantagens oferecidas por um corpus de aprendizes, no que diz respeito à identificação das áreas em que os aprendizes tendem a usar "estratégias de evitação" e, por conseguinte, deixam de explorar profundamente o potencial da língua alvo.

É possível, também, investigar assuntos relacionados a "foreign soundingness", conceito dado por Pravec (2002), na escrita de aprendizes de inglês como LE (ou qualquer outra língua), que pode ser detectado ao levantar e analisar, por exemplo, quais estruturas gramaticais, linguísticas, lexicais, discursivas ou pragmáticas são empregadas de forma restrita (subuso) ou excessiva (sobreuso) por parte dos referidos aprendizes, em relação a falantes nativos.

No que se refere à influência da L1 na produção escrita ou oral dos aprendizes de uma LE, por exemplo, a questão da transferência, os corpora de aprendizes podem contribuir de maneira significativa, conforme aponta Tono (1999). De modo mais específico, pesquisadores como De Cock (1998), Granger (1998b), Granger, Hung e Petch-Tyson (2002), Paquot (2008), Nesselhauf (2005), entre outros, tratam da influência da L1 na produção de unidades multipalavras (multiword sequences). Nesta pesquisa, será possível observar a influência da L1 na produção da unidade multipalavra do tipo colocação na língua inglesa.

Além disso, corpora de aprendizes possibilitam analisar o desempenho de um falante quase nativo em relação ao falante fluente da língua inglesa e a identificar dificuldades específicas do aprendiz de uma dada língua de partida. Leech (1998) também menciona que, por meio da exploração de corpora de aprendizes, é possível detectar quais são as áreas nas quais os aprendizes de um dado país parecem necessitar mais de ajuda para desenvolver sua produção na língua-alvo. 
Segundo pode ser notado, os corpora de aprendizes, por fornecerem um instrumental eficaz de apresentação e exploração de dados, abriram novas perspectivas para investigações em ensino e aquisição de LE, possibilitando a pesquisadores e professores da área, diferentes maneiras de contribuir para uma melhoria no ensinoaprendizagem de LE.

Em relação a corpora de aprendizes de tradutor, são vários os autores que apontam sua relevância (BOWKER, 2000; BERBER SARDINHA, 2001; ORENHA-OTTAIANO, 2012, entre outros), no sentido de promover melhor compreensão do processo tradutório, bem como facilitar a tarefa do próprio aprendiz de tradutor na busca pela melhor opção tradutória. Segundo Orenha-Ottaiano (2012), o uso de corpora para a formação de tradutores tem se mostrado extremamente eficiente, principalmente, no que tange à conscientização do aspecto fraseológico e convencional da língua, assim como às especificidades da terminologia de determinadas áreas de especialidade.

\section{Metodologia}

Com base no arcabouço teórico relatado, esta seção trata da metodologia de pesquisa que está sendo empregada para a realização desta investigação. Abordaremos os procedimentos para a compilação dos corpora de aprendizes (CALE e CAT) e, na sequência, dos passos metodológicos para a extração das colocações, por meio do programa computacional WordSmith Tools (SCOTT, 2008), versão 5.0, e de novas combinatórias, com base na lista de frequência do COCA e com o auxílio do referido corpus de referência.

\subsection{A Compilação do Corpus de Aprendizes de Tradução (CAT)}

O CAT, por ser um corpus paralelo, é formado por textos originalmente escritos em inglês e seus respectivos textos traduzidos pelos alunos envolvidos na pesquisa $\left(2^{\circ}\right.$ e $3^{\circ}$ ano do Curso de Tradutor, em um total de 18 alunos), no Laboratório para o Ensino de Línguas Estrangeiras, em horário extraclasse. Os participantes tinham 
aproximadamente duas horas para traduzir um texto de aproximadamente 800 palavras. Ao finalizar, enviavam as traduções para a pesquisadora em arquivos identificados.

Quanto à tipologia dos textos, trata-se de textos jornalísticos, retirados de jornais ou revistas de grande circulação no país, ou seja, todos os textos originais foram escritos em português e vertidos para o inglês. Em relação aos temas, foram selecionados tópicos discutidos internacionalmente, tais como: "Morte de Kadafi"; "Um ano depois do Terremoto no Japão"; "Crise financeira na Grécia e na Europa"; "Desemprego"; "Bullying"; "Legalização da maconha"; "Eleições nos Estados Unidos", "Aborto", "Eutanásia" etc. Outros gêneros de textos estão sendo inseridos ao corpus nos últimos meses, que também servirão de extração e posterior análise de colocações. Cabe lembrar, que tanto os textos originais quanto os textos traduzidos são salvos em extensão .txt, a fim de serem processados pelo programa WordSmith Tools (SCOTT, 2008).

3.2 A Compilação do Corpus de Aprendizes de Língua Escrita (CALE)

O CALE é formado pelas redações dos alunos dos cursos de Letras e Tradutor, segundo mencionado. Baseado no projeto ICLE, coordenado por Granger (1993), os textos dos aprendizes são, na sua maioria, argumentativos. Da mesma forma que o ICLE, há alguns temas que os alunos devem seguir para escrever seus textos, temas esses previamente determinados pela professora-pesquisadora, na expectativa de que tal seleção suscitasse ideias para a escrita dos textos. Alguns dos temas selecionados foram: 
Quadro 1 - Temas para a elaboração de textos escritos

\begin{tabular}{|c|c|c|c|}
\hline $1^{0}$ ano & $2^{\circ}$ ano & $3^{0}$ ano & $4^{0}$ ano \\
\hline $\begin{array}{l}\text { Only one child-- } \\
\text { lonely child? }\end{array}$ & $\begin{array}{c}\text { Stories about } \\
\text { things that went } \\
\text { wrong }\end{array}$ & Abortion & $\begin{array}{l}\text { Genetically- } \\
\text { modified food }\end{array}$ \\
\hline Friendship & Longevity & Brain power & Global Warming \\
\hline $\begin{array}{c}\text { Country life or city } \\
\text { life? }\end{array}$ & $\begin{array}{l}\text { Marriage and } \\
\text { tradition }\end{array}$ & $\begin{array}{l}\text { Financial Crises } \\
\quad \text { in Europe }\end{array}$ & Addiction/Drugs \\
\hline $\begin{array}{l}\text { Finding the ideal } \\
\text { job }\end{array}$ & $\begin{array}{c}\text { One year after } \\
\text { Japan's } \\
\text { earthquake }\end{array}$ & Culture Shock & Euthanasia \\
\hline Staying healthy & Unemployment & Bullying & $\begin{array}{c}\text { Capital } \\
\text { Punishment }\end{array}$ \\
\hline \multirow[t]{3}{*}{ My last vacation } & Lies and Truth & $\begin{array}{c}\text { Positive and } \\
\text { negative effects of } \\
\text { TV viewing }\end{array}$ & Advertisement \\
\hline & Happiness & Stereotypes & $\begin{array}{l}\text { Same-sex } \\
\text { marriage }\end{array}$ \\
\hline & & Religion & Censorship \\
\hline
\end{tabular}

Fonte: nossa autoria.

Além desses, outros temas da atualidade, presentes nos jornais, revistas e materiais didáticos, foram selecionados para esta pesquisa.

Quanto à extensão dos textos escritos, as redações deveriam conter, para este estudo:

- de 200 a 350 palavras para os alunos do primeiro ano de ambos os cursos;

- de 300 a 450 palavras para os alunos do segundo ano;

- de 400 a 650 palavras para os alunos do terceiro ano; e

- de 800 a 1.000 palavras para os alunos do quarto ano. 
Os textos também foram salvos em formato .txt, e enviados pelos alunos à docente-pesquisadora, via e-mail. Coube à pesquisadora deixar claro para os alunos que suas redações seriam utilizadas para fins de pesquisa e que seus nomes seriam mantidos em sigilo. Dessa forma, os alunos assinaram um documento permitindo a utilização de seus textos para essa finalidade. Essa decisão está apoiada no texto da British Association for Applied Linguistics (THOMPSON, 2005), cuja sugestão é de que a autorização de dados seja gravada nos mesmos meios da coleta de dados: por vídeo ou áudio, ou, no caso do CALE e do CAT, na forma escrita.

3.3 Procedimentos para levantamento e análise das colocações para sua inserção no Workbook

Por questões de delimitação, apresentamos, neste item, o levantamento de algumas colocações extraídas apenas do CAT, uma vez que, por conta desse levantamento, outras combinatórias serão extraídas do $C O C A$, tomando como ponto de partida a base dessas colocações (HAUSMANN, 1985). De posse dessas colocações, estão sendo elaborados os exercícios ou jogos colocacionais, os quais empregam as referidas colocações extraídasA partir da observação de algumas palavras-chave do CAT, apresentadas no quadro abaixo, especificamente dos textos traduzidos para o inglês, selecionamos duas (resistance e primary) e, a partir desta seleção, geramos linhas de concordâncias, por meio da ferramenta Concord, para fins de levantamento e análise das colocações.

Quadro 5 - Quatorze primeiras palavras-chave do CAT

\begin{tabular}{|l|l|}
\hline 1. Primaries & 3. Caucus \\
\hline 2. Dictator & 9. Revolutionary \\
\hline 3. Resistance & 10. Elections \\
\hline 4. Republican & 11. Contribution \\
\hline 5. Priors & 12. Announce \\
\hline 6. Marijuana & 13. Leader \\
\hline 7. Delegates & 14. Regime \\
\hline
\end{tabular}


A título de exemplificação, apresentamos as linhas de concordância do termo resistance:

\section{Figura 2 - Linhas de concordância da palavra-chave resistance}

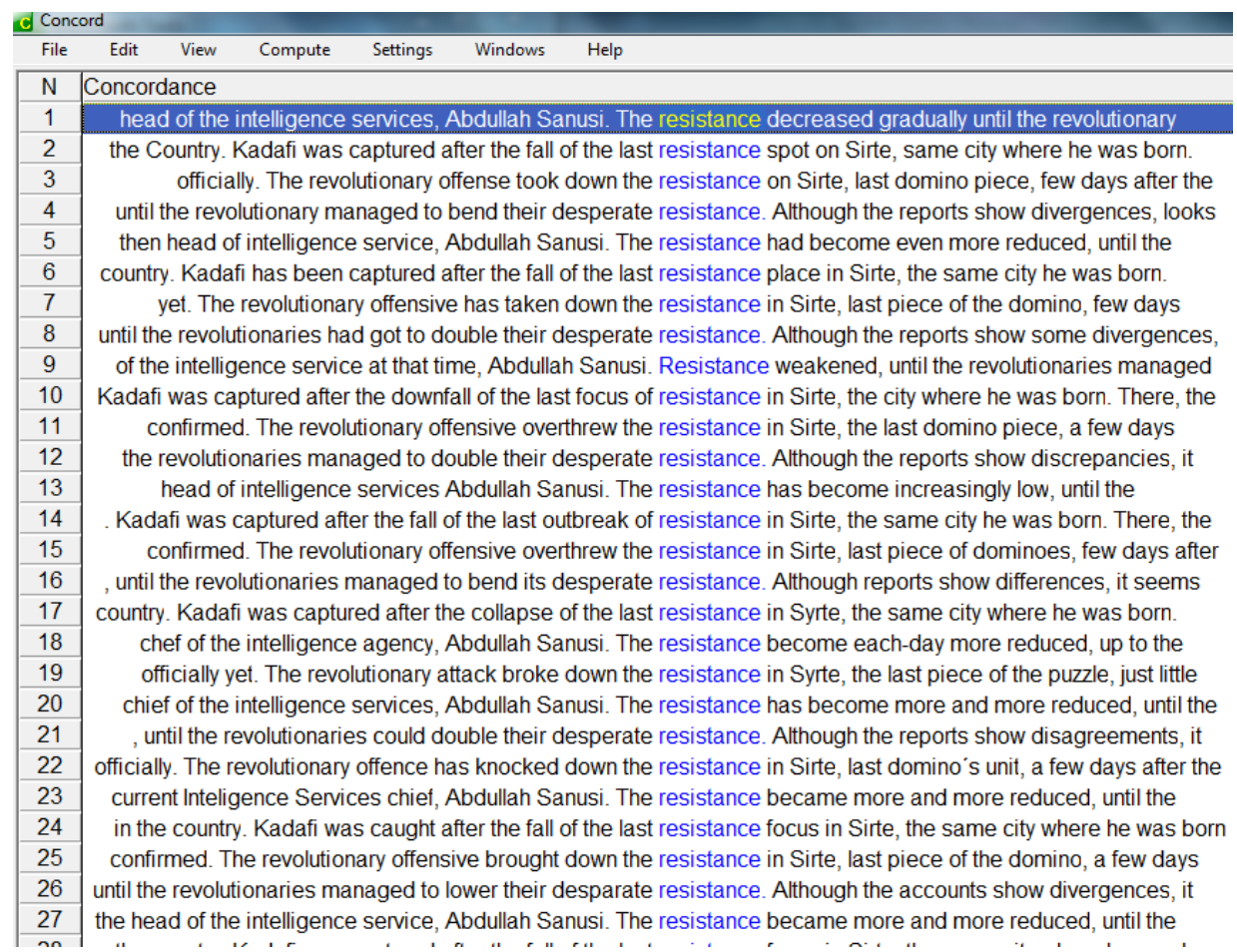

A palavra-chave resistance foi traduzida, por exemplo, de um dos contextos dos textos originais: "A ofensiva revolucionária derrubou a resistência (...])". Para essa colocação em português, levantamos as colocações em inglês no CAT, abaixo elencadas na Tabela 1. A fim de verificar se as escolhas colocacionais feitas pelos alunos são recorrentes na língua inglesa, verificamos sua recorrência no $C O C A$. No entanto, em virtude de serem colocações verbais muito específicas, de um contexto mais especializado, a frequência levantada foi muito baixa, não sendo possível afirmar se eram realmente frequentes na língua inglesa. Dessa maneira, essas colocações foram também investigadas na $W e b$, por meio da ferramenta de busca Google. Vale mencionar, que as buscas foram 
realizadas com os verbos no tempo verbal em que se encontravam os verbos no contexto analisado, ou seja, no passado (Simple past - Ex.: took down the resistance), com exceção da combinação upend the resistance, uma vez que preservamos a forma como foi utilizada na tradução, segundo apresentamos a seguir:

Tabela 1 - Lista dos possíveis colocados do nódulo resistance

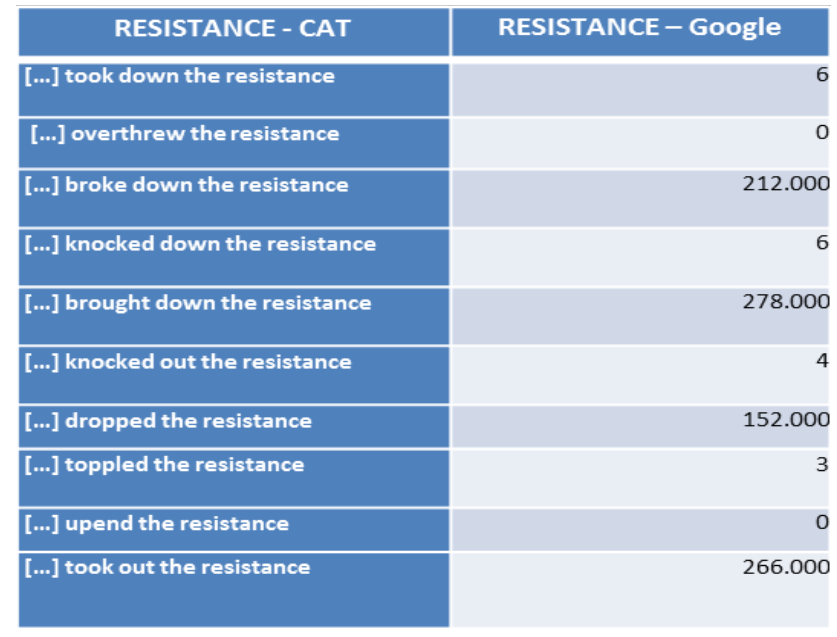

Conforme pode ser notado na Tabela 1, em razão de se tratar de um corpus paralelo, fica muito interessante verificar as diversas possibilidades tradutórias sugeridas pelos alunos: por meio de uma colocação em português ("derrubar a resistência"), tivemos 10 opções tradutórias dos 18 alunos envolvidos na pesquisa, ou seja, algumas dessas opções foram empregadas por mais de um aluno. Vale mencionar a rapidez com que essas colocações foram geradas pelo programa WordSmith Tools.

Podemos observar que $40 \%$ das possibilidades tradutórias acima elencadas são recorrentes em inglês e comumente empregadas nessa língua: broke down the resistance (212.000 ocorrências), brought down the resistance (278.000), dropped down the resistance (152.000) e took out the resistance (266.000 ocorrências). No entanto, as demais combinações empregadas pelos alunos de tradução parecem não ser recorrentes: overthrew the resistance (0 ocorrência no Google), knocked 
down the resistance (6 ocorrências), knocked out the resistance (4 ocorrências), e toppled the resistance (3 ocorrências) e upend the resistance (0 ocorrência)

Esse resultado, somado a outros casos semelhantes levantados durante a análise das colocações baseada no CAT com base em outras palavras-chave, pode indicar que, mesmo aprendizes com nível de conhecimento de língua mais avançado, podem não ter consciência do aspecto colocacional da língua, considerando que os alunos investigados tiveram acesso à Internet e a dicionários (impressos e online) para realizar as traduções.

Os resultados dessa investigação serviram de motivação para a compilação do workbook proposto, evidenciando sua relevância para o ensino de inglês como LE. No item seguinte, trataremos dos aspectos relacionados à elaboração do Online English Collocations Workbook.

\section{Da elaboração do Online English Collocations Workbook}

O objetivo principal de nossa investigação é a compilação de um Online English Collocations Workbook, contendo colocações mais frequentemente empregadas na língua inglesa, com base nas colocações levantadas nos corpora de aprendizes e no corpus de referência on-line, atendendo, desse modo, às necessidades dos brasileiros aprendizes de inglês como LE. O material de apoio pedagógico proposto apresenta-se como uma resposta às dificuldades enfrentadas por aprendizes brasileiros da língua inglesa, no que concerne ao aprendizado de colocações. Os exercícios que compõem o workbook são de cunho prático, visando auxiliar aos alunos incorporá-las a seu léxico mental, principalmente, por meio de jogos e de forma interativa e divertida.

Outro motivo que justifica sua compilação é a escassez de materiais de apoio que contemplem unidades fraseológicas do tipo colocação. Mackin (1978) já defendia a criação de materiais como o proposto:

O que os professores de inglês como LE precisam, para um treinamento eficaz de competência 
colocacional (na condição de que [as turmas] sejam homogêneas em relação à L1), são livros de exercícios que contenham uma seleção de colocações direcionadas às dificuldades específicas dos aprendizes (...). Tais materiais permitiriam-nos realmente ensinar colocações e, dessa maneira, diminuir, pelo menos até certo ponto, o longo e árduo processo de aquisição da competência colocacional, durante anos de estudo, leitura e observação da língua (MACKIN, 1978, p. 151). ${ }^{18}$

Dessa maneira, é possível notar a relevância da obra proposta para alunos de inglês como LE. Esperamos, por meio desta pesquisa, poder contribuir para que os aprendizes atinjam o caminho da fluência, produzindo textos (orais ou escritos) mais idiomáticos e naturais.

Segundo citamos na introdução desta proposta, esta investigação pretende, devido à complexidade na elaboração dos exercícios colocacionais e da plataforma on-line, bem como a questões de delimitações orçamentárias, contemplar a primeira e a segunda fase de elaboração do workbook, disponibilizando, dessa maneira, o jogo da memória (Memory Game) e a atividade "Completar espaços" (Gap Fill), que consiste em completar frases ou trechos de textos por meio de colocações pré-definidas. Essa plataforma está sendo elaborada pelo Grupo de Banco de Dados (GBD), sob coordenação do Prof. Dr. Carlos Roberto Valência, do Departamento de Computação, da UNESP.

Vale mencionar que alguns dos exercícios já compilados (Memory game e Gap fill) já foram aplicados em sala de aula para os professores inscritos no Curso de Extensão (de Aperfeiçoamento) "Linguística de Corpus e Fraseologia aplicadas à prática pedagógica de Professores de Língua Inglesa da Rede Pública”, com carga horária de 180 horas, de agosto de 2013 a julho de 2014. Este curso faz parte de um

18 "What EFL teachers need for an effective training of collocational competence in their classes (as long as these are homogenous with regard to the L1) are workbooks presenting a selection of collocations geared to the specific difficulties of learners (...). Such material would allow us to actually teach collocations and thus shorten, at least to a certain extent, the long and laborious process of acquiring collocational competence through years of study, reading, and observation of the language". 
Projeto de Extensão de mesmo nome, aprovado pela PROEX em 2013, sob nossa coordenação. Além disso, os professores avaliaramm os exercícios e nos deram feedback referente à sua aplicabilidade e eficácia. Alguns desses professores, segundo consta, buscarão aplicar as atividades do workbook em suas aulas na rede pública e privada de ensino.

Para melhor ilustrar como está sendo realizada a compilação do Online English Collocations Workbook, apresentamos a seguir um dos jogos (Memory Game) e uma das atividades já disponíveis na plataforma do Workbook (Gap Fill) e algumas funcionalidades referentes à criação e ao gerenciamento dos jogos, gerenciamento de usuários, entre outros aspectos.

Ao acessar o material, o consulente abre a uma tela, explicando o que é o Online English Collocations Workbook, conforme figura abaixo:

Figura 3 - Plataforma de acesso ao Workbook on-line

\section{Online English Collocations Workbook}

\begin{tabular}{|l|l|}
\hline Email address: & Welcome to Online English Collocations Workbook, an interactive platform to learn \\
collocations, specially designed to native Brazilian Portuguese speakers, learners of \\
English as a foreign language. \\
This design of this Workbook is part of an ongoing and larger research project carried \\
out at ame@example.com
\end{tabular}

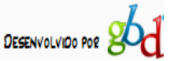

Para obter acesso ao workbook, haverá dois tipos de usuários: 1) a coordenadora do projeto, responsável pelo gerenciamento e cadastro de 
novos exercícios e pela liberação do acesso aos usuários e gerenciamento de seus dados; 2) o público de modo geral, que terá acesso ao sistema para fazer os exercícios e jogos de colocação, mediante cadastro. Desse modo, para acessar o workbook, o usuário deverá fazer um cadastro, conforme a figura a seguir:

Figura 4 - Tela de cadastro para acesso ao Online English Collocations Workbook

\section{Online English Collocations Workbook}

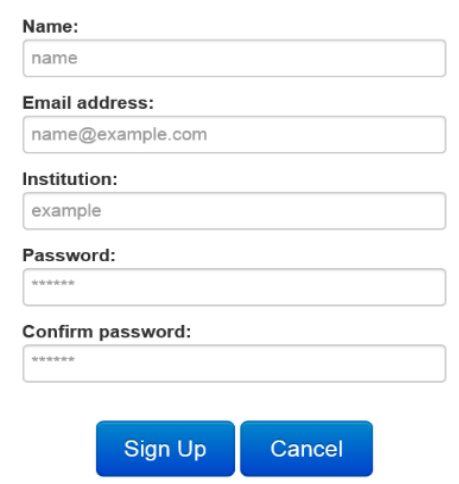

O administrador do sistema (a coordenadora do projeto) receberá a mensagem e poderá autorizar ou não o acesso daquele usuário à plataforma, além de gerenciar os usuários cadastrados, segundo tela abaixo: 
Figura 5 - Tela do Administrador para gerenciamento dos usuários do Workbook
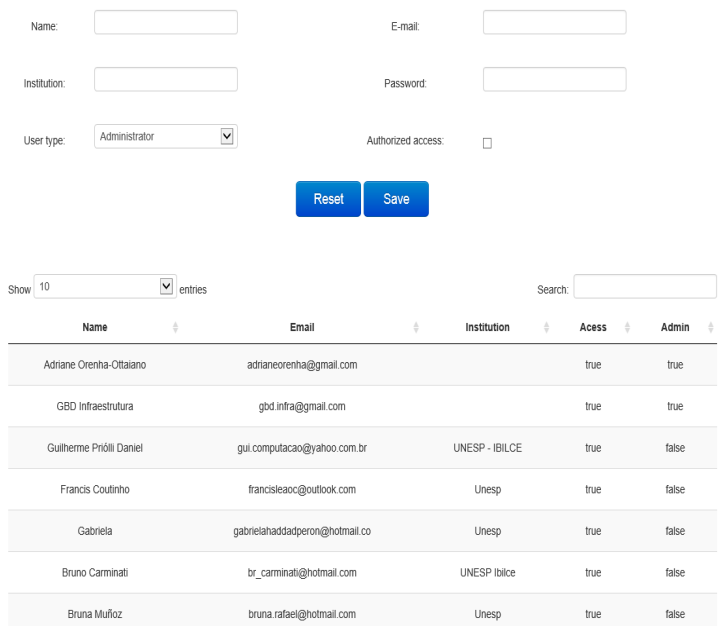

A figura a seguir mostra a aba Report, por meio da qual o usuário pode reportar problemas ou erros encontrados ao realizar os exercícios ou jogos e enviá-los para a equipe do GBD, que os discutirão com a coordenadora do projeto:

Figura 6 - Tela de teste do usuário para reportar problemas

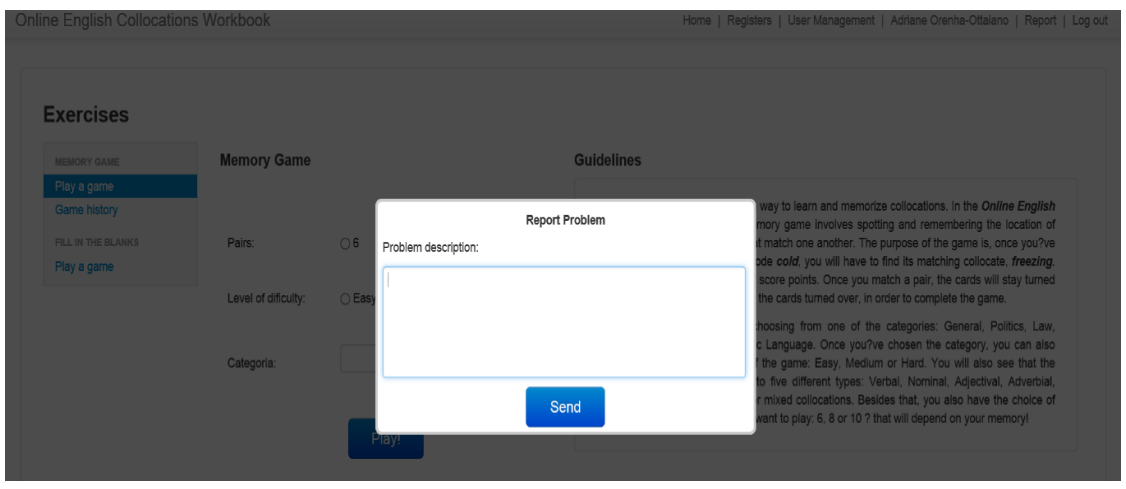


Durante as reuniões com GBD, no processo de definição e provimento de recursos das interfaces do sistema, ficou decidido que tanto o Memory game quanto o Gap Fill trarão atividades bastante interativas e com diferentes níveis de dificuldade (fácil, médio e difícil), segundo mostra a figura abaixo:

Figura 7 - Tela com os níveis de dificuldade das atividades colocacionais

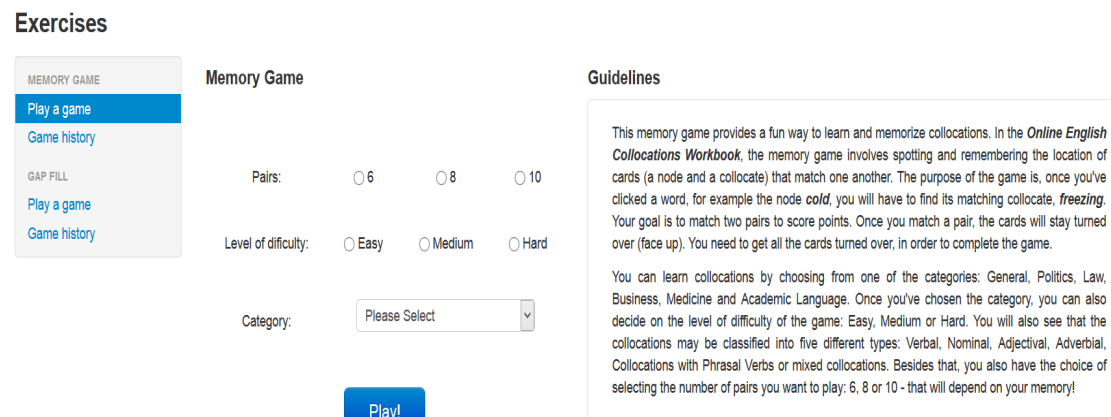

Além dos níveis, o usuário poderá optar pelo número de pares que gostaria de jogar (vai depender de sua memória!), e também por categorias das quais o usuário poderá selecionar Academic Language, Business, General, Medicine e Politics, a fim de trabalhar com colocações de diferentes áreas ou da língua geral (General). Futuramente, novas categorias serão inseridas: 
Figura 8 - Tela com as categorias focadas no glossário

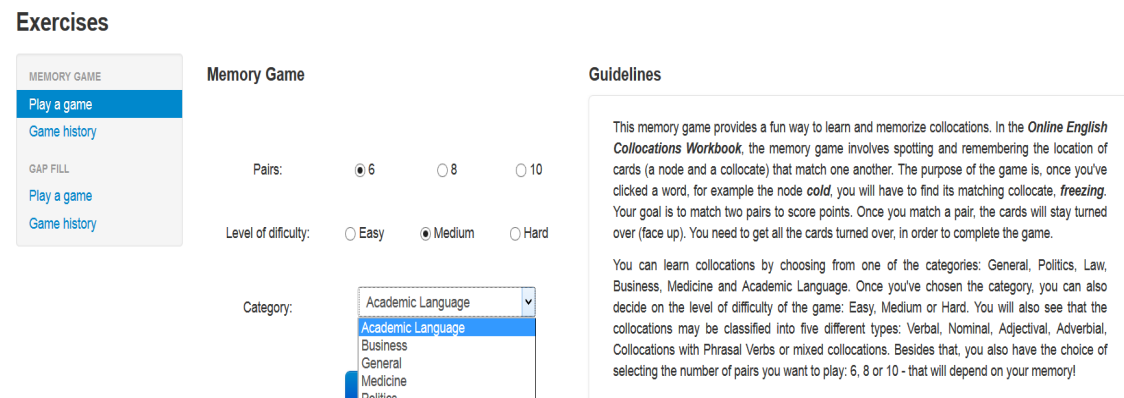

No que se refere ao Memory Game, ao clicar em Play a game, o usuário receberá uma mensagem de que terá 10 segundos para tentar memorizar os pares de palavras que formarão uma colocação e deverá clicar em OK para visualizá-las: You have 10 seconds to memorize the location of the pairs of the same color. At the end of the 10 seconds, all words will be hidden and you will start to play the Memory Game.

Figura 9 - Tela de aviso para memorização das palavras que formam as colocações

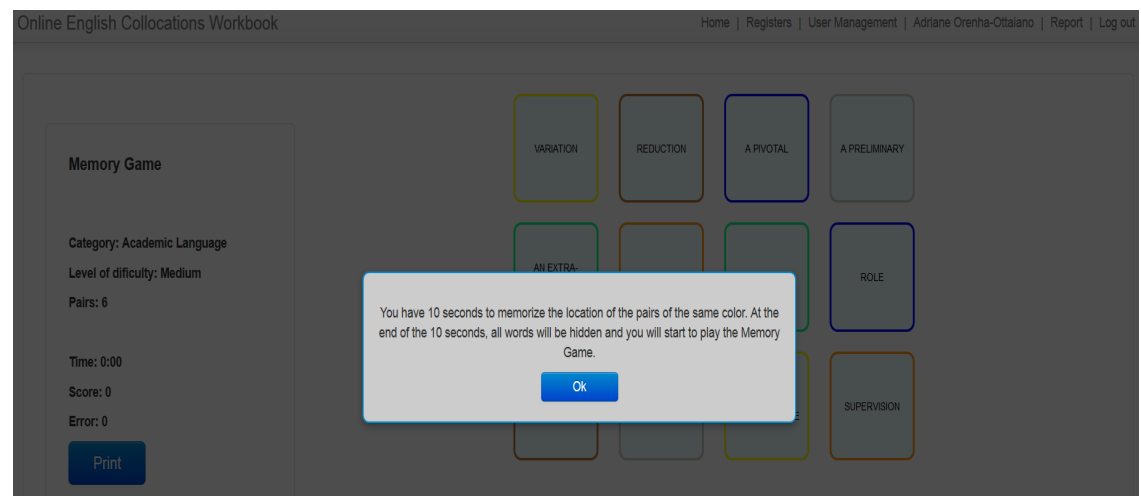


Abaixo, apresentamos a tela com todas as palavras que formarão colocações. Conforme pode ser notado, cada par de palavras está em uma cor, a fím de mostrar ao usuário a colocação formada e facilitar a memorização de sua localização no quadro:

Figura 10 - Tela para memorização das colocações
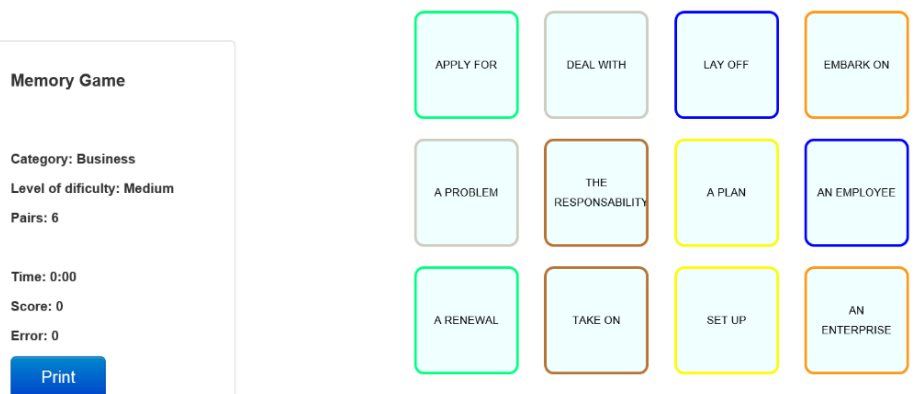

Quando o tempo dessa parte da atividade chega ao fim, aparece uma tela informando que o usuário poderá iniciar o jogo.

Figura 11 - Tela informando que jogo pode ser iniciado
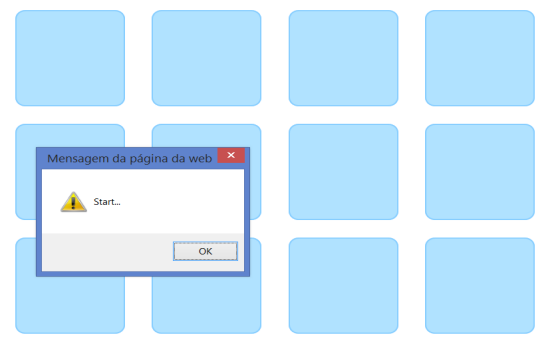
A figura a seguir mostra o usuário jogando o Memory Game, em busca dos pares que formarão as colocações. Observe que, no lado esquerdo da tela do jogo, há um resumo de escolhas que o usuário pode fazer: a categoria (Category), o nível de dificuldade (Level of difficulty), o número de pares selecionado (Pairs), bem como o tempo para realizar o jogo (Time), sua pontuação (Score) e o número de erros (Errors):

Figura 12 - Jogando o Memory Game

Online English Collocations Workbook

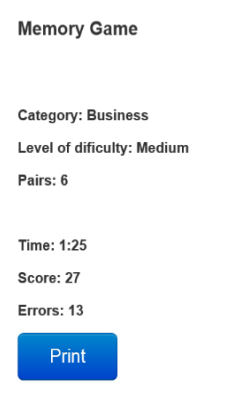

Home | Registers | User Management | Adriane Orenha-Ottaiano | Report | Log out

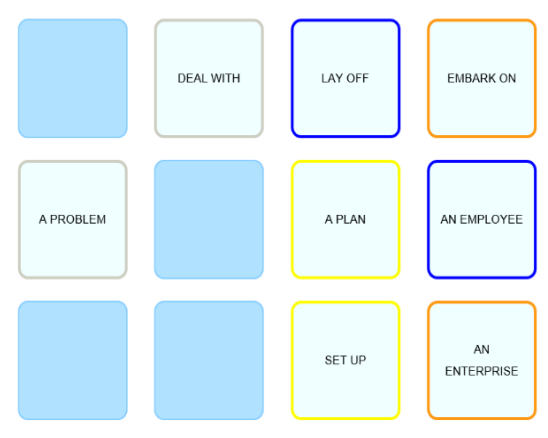

$\mathrm{Na}$ figura seguinte, apresentamos a tela do exercício Gap fill, seguindo o mesmo padrão do Memory Game. A única diferença é que ele já oferece ao usuário a opção de escolher, além dos níveis de dificuldade e da categoria, a tipologia das colocações (taxonomy) que gostaria de trabalhar: Verbal, Nominal, Adjectival e Adverbial - já providenciamos a correção dos referidos tipos de colocações na plataforma. Vale ressaltar que essa opção também será oferecida para o Memory Game em breve. 
Figura 13 - Tela de seleção de itens para realizar o exercício Gap Fill

\section{Exercises}

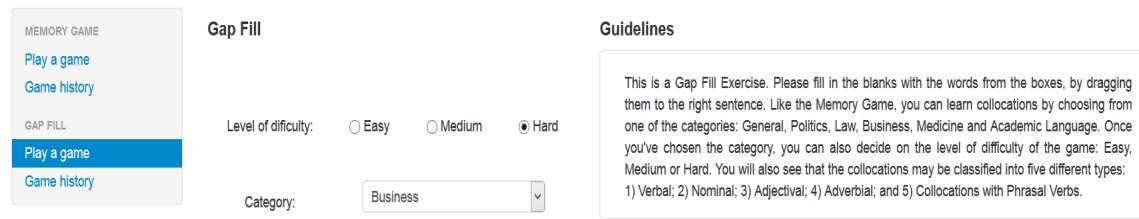

Na Figura 14, é possível ver uma tela em que o usuário irá iniciar o exercício Gap Fill. O usuário foi orientado a arrastar, neste caso, os verbos que formarão as colocações contextualizadas nos exercícios, para preencher as lacunas. Muitas das colocações que compõem os exercícios de exercício Gap Fill são trabalhadas no Memory Game e que, neste momento, o usuário tem a oportunidade de observá-las novamente em contexto.

Figura 14 - Tela com exemplo de um exercício do tipo exercício Gap Fill

Fill in the blanks
Taxonomy: VERBAL COLLOCATIONS
Category: Eusiness
Level of dificulty: Hard
Time: $0: 12$
Score: 01500
Attempts: 0

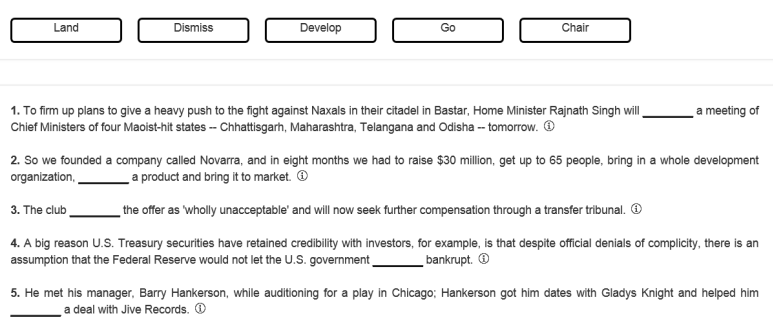


A Figura 15 mostra como os verbos são arrastados pelo usuário até a oração que formaria a colocação:

Figura 15 - Usuário arrastando um verbo que formará uma colocação em contexto

Fill in the blanks
Taxonomy: VERBAL COLLOCATIONS
Category: Business
Level of dificulty: Hard
Time: 1:07
Score: 01500
Attempts: 0

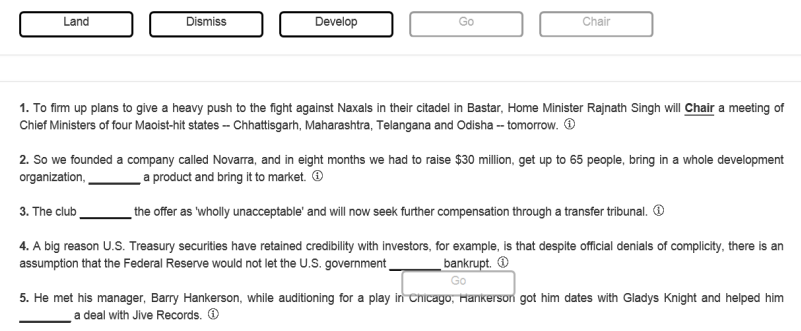

Uma vez completado o exercício, o usuário pode clicar em Check, a fim de verificar se suas opções estariam corretas. Ao fazer isso, obterá o seguinte resultado:

Figura 16 - Correção do exercício de Gap Fill

Gap Fill

TaXonomy: VERBAL COLLOCATIONS

Category: Business

Level of dificulty: Hard

1. Ozark Mountain Pouttry, a regional competitor, says it hopes to Close a deal to take over the ConAgra plant. (1)

Time: 0:19

Score: $500 / 500$ 2. Greek Prime $M$

Attempts: 1

3. So we founded a company called Novara, and in elght months we had to ralse $930 \mathrm{millilon}$, get up to 65 people, bring in a whole development organization, Develop a product and bring it to market. (1)

4. If you want to Open a company in Russia and you don't want to go to this country, our lawyers in Russia will help you with the entire registration procedure. (i)

5. In this way, the business can Decline an offer if, for example, the product in question is out of stock or the price is misquoted. (1) 
Segundo pode ser observado na Figura 17, ao clicar no ícone (i), o usuário terá acesso à fonte do contexto em que as colocações empregadas foram retiradas:

Figura 17 - Fonte do contexto em que as colocações empregadas foram retiradas

Fill in the blanks

Taxonomy: VERBAL COLLOCATIONS

Category: Business

Level of dificulty: Hard

Time: 1:51

Score: $500 / 500$

Attempts: 1

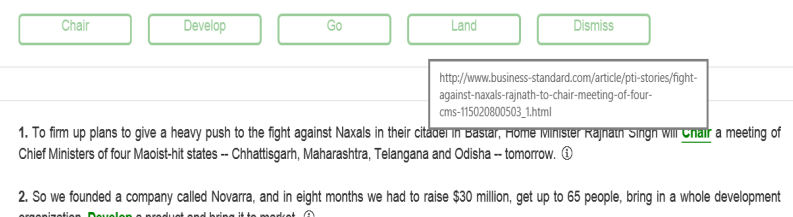

2. So we founded a company called Novarra, and in eight
organization, Develop a product and bring it to market. (i)

3. The club Dismiss the offer as 'Wholly unacceptable' and will now seek further compensation through a transfer tribunal. (i)

4. A big reason U.S. Treasury securities have retained credibility with investors, for example, is that despite official denials of complicity, there is an assumption that the Federal Reserve would not let the U.S. government Go bankrupt. (i)

5. He met his manager, Barry Hankerson, while auditioning for a play in Chicago; Hankerson got him dates with Gladys Knight and helped him Land a deal with Jive Records. (i)

Se o aprendiz clicar em Registers, na tela de abertura do Workbook, ele terá acesso à lista de todas as colocações com as quais ele já trabalhou: 
Figura 18 - Lista de todas as colocações estudadas

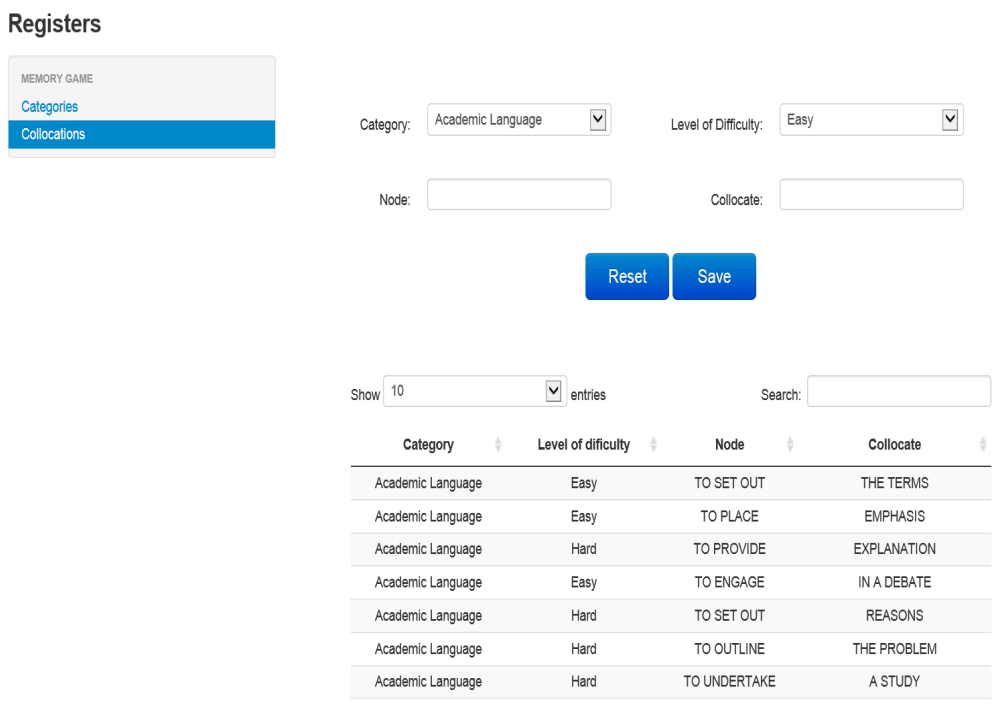

Além do Memory Game e do Gap Fill, outros tipos de exercícios ou jogos serão elaborados e inseridos na plataforma do Workbook, por exemplo, um jogo de Domino (Dominó).

\section{Considerações Finais}

Conforme o relato de elaboração do Online English Collocations Workbook, consideramos que a pesquisa aqui relatada tenha relevância científica para o público-alvo, dada sua proposta original e seu caráter inédito. Até o presente momento, desconhecemos um material de apoio publicado no Brasil que, primeiramente, enfoque as colocações e que, em segundo, seja direcionado especificamente a brasileiros aprendizes de inglês como língua estrangeira, de modo a viabilizar um aprendizado mais sistemático e, ao mesmo tempo, interativo, das colocações. Isso se dá, uma vez que as atividades estão sendo desenvolvidas com base nas 
dificuldades que alunos brasileiros tiveram em relação ao uso de colocações, segundo dados observados em traduções de alunos universitários que compõem o Corpus de Aprendizes de Tradução, bem como de redações, também escrita por alunos universitários, que compõem o Corpus de Aprendizes de Língua Estrangeira. Dessa maneira, esta investigação propõe preencher uma lacuna referente à escassez de obras fraseológicas no país, além de disponibilizar um material didático como uma resposta às dificuldades enfrentadas por aprendizes brasileiros da língua inglesa quanto ao aprendizado de colocações.

Nesse sentido, o material pedagógico aqui exposto poderá contribuir para a divulgação da importância do ensino de colocações, especialmente pelo fato de estar disponível on-line, possibilitando mais visibilidade das pesquisas realizadas aqui no Brasil, possibilitando um acesso a um número maior de aprendizes e professores. Outro fator determinante de sua relevância se fundamenta na demanda já constatada para a disponibilização do referido material de apoio na $\mathrm{Web}$, por parte de alunos universitários e, principalmente, de professores da rede pública e privada.

\section{Referências}

ALTENBERG, B.; EEG-OLOFSSON, M. Phraseology in Spoken English: presentation of a Project. In: AARTS, J.; MEIJS, W. (Ed.). Theory and practice in Corpus Linguistics. Amsterdam: Randpi, 1-26, 1990.

ANTHONY, L. AntConc. 2012. Disponível em: $<$ http://www.antlab.sci.waseda.ac.jp/ software.html $>$. Acesso em: 17 fev. 2014.

BAHNS, J.; ELDAW, M. Should we teach EFL students collocations? System, v. 21, n. 1, p. 101-114, 1993.

BERBER SARDINHA, A. P. Linguística de Corpus. Barueri, SP: Editora Manole, 2004. 
. O corpus de aprendiz Br-ICLE. In: XI InPLA, 2001, São Paulo. Intercâmbio 10. São Paulo: EDUC, p. 227-239. Disponível em: $<$ http://www2.lael.pucsp.br/ tony/temp/ publications/2001bricleinterc.pdf $>$. Acesso em: 18 fev. 2010.

BERNARDINI, S. Corpora in the classroom: an overview and some reflections on future developments. In: SINCLAIR, J. McH. How to use corpora in language teaching, 2004. DOI: $<$ http://dx.doi.org/10.1075/scl.12.05ber $>$

DAVIES, M. The Corpus of Contemporary American English: 450 million words, 1990-present. Disponível em: $<$ http://corpus.byu.edu/COCA/ > . Acesso em: 20 de fev. 2014.

DE COCK, S. An automated approach to the phrasicon of EFL learners. In: GRANGER, S. (Org.). Learner English on Computer. London and New York: Longman, 1998, p. 67-79.

FILLMORE, C. J. Innocence: a second idealization for Linguistics. Berkeley Linguistic Society, v. 5, p. 63-76, 1979.

FIRTH, J. R. Modes of Meaning. In: FIRTH, J. R. (Ed.). Papers in Linguistics - 1934-1951. Oxford: Oxford University Press, 1957.

FONTENELLE, $T$. Towards the construction of a collocational database for translation students. Meta XXXIX, v. 39, n. 1, 1994.

GRANGER, S. The International Corpus of Learner English. In AARTS, J.; DE HAAN, P.; OOSTDIJK, N. (Ed.) English Language Corpora: Design, Analysis and Exploitation. Amsterdam: Rodopi, 1993, p. 57-69.

- Learner English on Computer. London and New York: Longman, 1998a.

. Prefabricated patterns in advanced EFL writing: collocations and formulae. In: COWIE, A. (Ed.). Phraseology: theory, analysis and applications. Oxford: OUP, 1998b. p. 145-160.

GRANGER S.; HUNG, J.; PETCH-TYSON, S. Computer learner corpora, second language acquisition and foreign language teaching. 
Amsterdam/Philadelphia: John Benjamins, 2002. DOI: $<$ http://dx.doi.org/10.1075/11lt.6>

HALLIDAY, M. A. K. Lexical Relations. System and Function in Language: selected papers. Oxford, England: Oxford University Press, p. 73-83, 1961.

HAUSMANN, F. J. Wortschatzlernen ist Kollokationslernen. Zum Lehren und Lernen französischer Wortverbindungen. Praxis des neusprachlichen Unterrichts, 31, 1984, p. 395 - 406.

. Kollokationen im deutschen Wörterbuch. Ein Beitrag zur Theorie des lexikographischen Beispiels. In: BERGENHOLTZ, H; MUGDAN, J (Ed.). Lexikographie und Grammatik. Tubingen: Niemeyer, 1985.

Grundprobleme des zweisprachigen Wörterbuchs. In: INTERNATIONAL SYMPOSIM ON LEXICOGRAPHY, 3., May 1416, 1986, Tubingen. Proceedings... Ed. K. Hyldgaard-Jensen; K. A. Zettersten, University of Copenhagen, Tubingen: Niemeyer, 1988. p. 137-154.

HEID, U.; MARTIN, W; POSCH, I. An Overview of approaches towards the description of collocations. Feasibility of standards for collocational description of lexical items. EUROTRA 7 - Report, Stuttgart/Amsterdam, 1991.

HEYLEN, D.; MAXWELL, K. Lexical functions and the translation of collocations. In: INTERNATIONAL CONFERENCE ON COMPUTATIONAL LINGUISTICS, 13., 1994, Kyoto. Proceedings... Kyoto, Japan, 1994. p. 298-305.

HILL, J. Revising priorities: from grammatical failure to collocational success. In: LEWIS, M. (Ed.). Teaching Collocation: further developments in the lexical approach. Croatia: Heinle, 2000. p. 47-69.

KJELLMER, G. A mint of phrases. In: AIJMER, K.; ALTENBERG, B. English corpus linguistics. Studies in honor of Jan Svartvik. London: Longman. p. 111-127. 
LEECH, G. Learner corpora: what they are and what can be done with them. In: GRANGER, S. Learner English on Computer. London and New York: Longman, 1998. p. xiv-xx.

MACKIN, R. On collocations: 'words shall be known by the company they keep'. In: STREVENS, P. (Ed.). In Honor of A. S. Hornby. Oxford: Oxford University Press, 1978.

MCINTOSH, C.; FRANCIS, B.; POOLE, R. (Ed.). Oxford Collocations Dictionary for Students of English. 2nd ed. Oxford: Oxford University Press, 2009. 963 p.

MEUNIER, F.; GRANGER, S. (Ed.). Phraseology in Foreign Language Learning and Teaching. Amsterdam \& Philadelphia: John Benjamins, 2008.

DOI: <http://dx.doi.org/10.1075/z.138>

NESSELHAUF, N. Collocations in a Learner Corpus. Amsterdam: John Benjamins, 2005.

ORENHA-OTTAIANO, A. English collocations extracted from a corpus of university learners and its contribution to a language teaching pedagogy. Acta Scientiarum. Language and Culture 34 (2), 214-251. 2012. DOI: <http://dx.doi.org/10.4025/actascilangcult>

. A compilação de um glossário bilíngue de colocações, na área de jornalismo de Negócios, baseado em corpus comparável. São Paulo, 2004. 246 f. Dissertação (Mestrado em Estudos Linguísticos e Literários), FFLCH/USP.

PAQUOT, 2008. Exemplification in learner writing: A cross-linguistic perspective. In: MEUNIER, F.; GRANGER, S. (Ed.). Phraseology in Foreign Language Learning and Teaching. Amsterdam \& Philadelphia: John Benjamins, 2008, p. 101-119. DOI: $<$ http://dx.doi.org/10.1075/z.138>

PAWLEY, A.; SYDER, F. H. Two Puzzles for linguistic theory: nativelike selection and nativelike fluency. In RICHARDS, Jack C.; 
SCHMIDT, Richard W. (Ed.). Language and Communication. London/New York: Longman, pp.191- 225, 1983.

PAWLEY, A.; SYDER, F. H. The One-Clause-at-a-Time Hypothesis. In RIGGENBACH, H. (Ed.), Perspectives on Fluency. Ann Arbor: The University of Michigan Press, 2000.

PRAVEC, N. A. Survey of learner corpora. In: ICAME Journal, No. 26, p.81-114, 2002.

SCOTT, M. WordSmith Tools: version 5.0. Oxford: Oxford University Press, 2008.

SEIDLHOFER, B. Closing a conceptual gap: the case for a description of English as a lingua franca. International Journal of Applied $\begin{array}{lllll}\text { Linguistics } & 11 & \text { (2): } 133-158, & 2001 . & \text { DOI: }\end{array}$ $<$ http://dx.doi.org/10.1111/1473-4192.00011>

SINCLAIR, J. McH. Corpus, concordance and collocation. Oxford: Oxford University Press, 1991.

SMIT, U. English as a lingua franca in higher education: a longitudinal study of classroom discourse. Germany: DeGruinter, 2010, p. 46. DOI: $<$ http://dx.doi.org/10.1515/9783110215519>

TAGNIN, S. E. O. Corpora and the Innocent Translator: how can they help him. In: THELEN, M (Ed.). Translation and Meaning, Part 6, Proceedings of the Lodz Session of the 3rd Maastricht-Lodz Duo Colloquium on Translation on Meaning, Lodz, Poland, September 22-24, 2000, Maastricht: Universitaire Pers Maastricht, p. 489-496, 2002.

TER-MINASOVA, Svetlana G. The Freedom of Word-Combinations and the Compilation of Learners' Dicitonaries . In: EURALEX '92 INTERNATIONAL CONGRESS ON LEXICOGRAPHY, 5. 1992, Tampere. Proceedings... Ed. H. Tommola, K. Varantola,

T. Salmi-Tolonen, J. Schopp. Tampere, Finland: University of Tampere, 1992. p. 533- 539.

THOMPSON, P. Spoken language corpora. In: WYNNE, M. (Ed.) Developing Linguistic Corpora: a Guide to Good Practice. Oxford: Oxbow Books, p. 59-70, 2005. Disponível em 
$<$ http://www.ahds.ac.uk/creating/guides/linguistic-corpora/index.htm $>$. Acesso em: 14 jan. 2010.

TOGNINI-BONELLI, E. Corpus linguistics at work. Studies in Corpus Linguistics, v. 6. Amsterdam: John Benjamins Publishing Company, 2001. DOI: <http://dx.doi.org/10.1075/scl.6>

TONO, Y. Using learner corpora in ELT and SLA research. In: AILA '99 - THE ROLES OF LANGUAGE IN THE $21{ }^{\text {st }}$ CENTURY: UNITY AND DIVERSITY, 12., 1-6 August 1999, Tokyo. Proceedings of the Symposium: The roles of corpora in language teaching and language engineering. Tokyo, Japan: Waseda University Press, 1999.

WRAY, A. Formulaic language and the lexicon. Cambridge: Cambridge University Press, 2002. DOI: $<$ http://dx.doi.org/10.1017/CBO9780511519772> 
